\title{
Study of Onset and Duration of Action of Local Anesthetic Eutectic Mixture in New Zealand White Rabbits
}

\author{
Article by Vijaykumar $\mathrm{S}^{1}$, Jagan $\mathrm{N}^{2}$, Jayasree $\mathrm{T}^{3}$ and Binoy Varghese Cheriyan ${ }^{4}$ \\ ${ }^{1}$ Department of Pharmacology, Asst. Professor, Mamatha Medical College and Hospital, \\ Telangana \\ ${ }^{2}$ Faculty of Medicine, Department of Pharmacology, Texila American University, Guyana, South \\ America \\ ${ }^{3}$ Dean, Mamatha Medical College \& Hospital, Khammam \\ ${ }^{4}$ Associate professor, VELS College of pharmacy, India \\ E-mail: vijaykumarsayeli@gmail.com
}

\begin{abstract}
The present study was designed to investigate the local anesthetic activity of EMLA cream on intact skin of hind limbs of New Zealand white rabbits by employing a novel method "Pedaling reflex in rabbits". Five different doses of drug ranging from 0.5 to $2.5 \mathrm{mg}$ was selected and applied to the ventral surface of the hind feet of both limbs. Uniform pressure was applied on anesthetized patches with help of a blunted probe. Six pricks were applied at different points on anesthetized patches and loss of pedaling reflex (leg retraction) followed by application of stimulus was considered as sign of anesthesia. A significant reduction in onset of anesthesia and a dose dependent increase in duration of anesthesia were recorded in the present study. The onset and duration of action for local anesthetic EMLA cream depends on dosage and contact time of drug on intact skin.
\end{abstract}

Keywords: White rabbit, EMLA cream

\section{Introduction}

Local anaesthetics are the drugs, which produce reversible loss of sensory perception especially pain in a restricted area of the body. Recent advances in medicinal chemistry lead to the development of newer local anaesthetics which are longer acting and suitable for using in multiple purposes. But these drugs are not effective when applied on intact skin. A variety of animal experiments are conducted to investigate the efficacy of local anaesthetics in animals and one among these experiments is infiltration anaesthesia conducted on guinea pigs (Vogel., 2002). Based on this reference, Activity of eutectic mixture of local anaesthetic (EMLA cream) on intact skin.

An attempt was made to develop a novel method, testing of leg retraction reflex (pedaling reflex) in New Zealand white rabbits to study the topical anaesthetic

\section{Material and methods}

New Zealand white rabbits were used in this study. All the animals were housed in animal house of Mamatha medical college with free access to food and water. The detailed study protocol was submitted to the institutional animal ethics committee and an approval was obtained before performing the study.

Inclusion criteria: only rabbits were selected.

- Both male and female rabbits were included.

- Rabbits weighing 2.5-3kg were included.

- All the rabbits were disease free.

- Animals exhibiting pedaling reflex of feet less than 4 seconds are included in this study.

Exclusion criteria: Drugs and chemicals- 5\% prilox cream (eutectic mixture containing Lidocaine and prilocaine). 
Texila International Journal of Basic Medical Science

Volume 2, Issue 1, Jul 2017

\section{Methods}

New Zealand white rabbits of either sex were selected for the study and they were divided in to five groups. Each group consists of six rabbits. These rabbits are kept in recumbent position, so that the fore limbs and hind limbs are exposed out. Remove hair on both the ventral surface of the hind feet and mark $2 \mathrm{sqcm}$

Circles in the center with marker so that the skin will be exposed out clearly. Test the retraction of limbs by probing with a blunt probe. Weigh the drug in five doses of $0.5 \mathrm{mg}, 1 \mathrm{mg}, 1.5 \mathrm{mg}, 2 \mathrm{mg}$ and 2.5mg.

Apply the first dose $0.5 \mathrm{mg}$ to the first group, second dose $1 \mathrm{mg}$ to the second group, third dose $1.5 \mathrm{mg}$ to third group, fourth dose $2.0 \mathrm{mg}$ to fourth group and fifth dose $2.5 \mathrm{mg}$ to the fifth group. The drug is applied to the patches with help of a spatula. Then occlude the patch for 5 minutes with the help of stickers provided with the medicament. After five minutes remove the stickers with help of forceps and test the retraction reflex by probing.

Pedaling reflex (Vogel 2002): The rabbit retracts the leg immediately when we apply pressure by probing the area with the help of a blunted probe. Six pricks are made on the anesthetized patches at different points. Loss of leg retraction (pedaling reflex) is considered as sign of complete anesthesia. The procedure was repeated after $5 \mathrm{~min}$ and for every 10 minutes until the leg retraction reappears.

Statistics: Results of the present study was analyzed by employing student Kruskal wall is test and $\mathrm{p}$ value less than 0.001 was considered as statistically significant

\section{Results}

The time taken for the onset and duration of anesthesia was recorded in all the EMLA treated groups. A significant reduction in onset of anesthesia was recorded in all the EMLA treated groups. Treatment with low dose of $0.5 \mathrm{mg}$, the mean onset of anesthesia for right leg is $10.84 \mathrm{~min}$ and for left leg is $13.33 \mathrm{~min}$ (Figure.1 \& Figure.2). However, treatment with high doses of $1.5 \mathrm{mg}, 2.0 \mathrm{mg}$ and $2.5 \mathrm{mg}$, the mean onset of action in both right and left leg remains constant i.e. 5min. A dose dependent and significant increase in duration of anesthesia was recorded in all the drug treated groups (Figure.1 \& Figure.3).

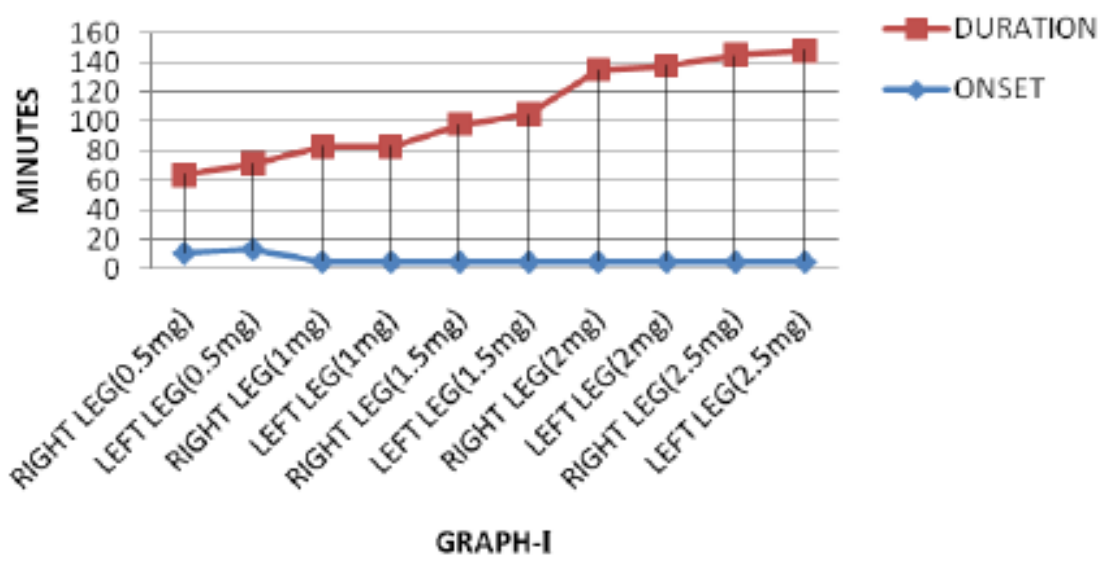

Figure. 1. Onset \& Duration of different doses of eutectic mixture. 


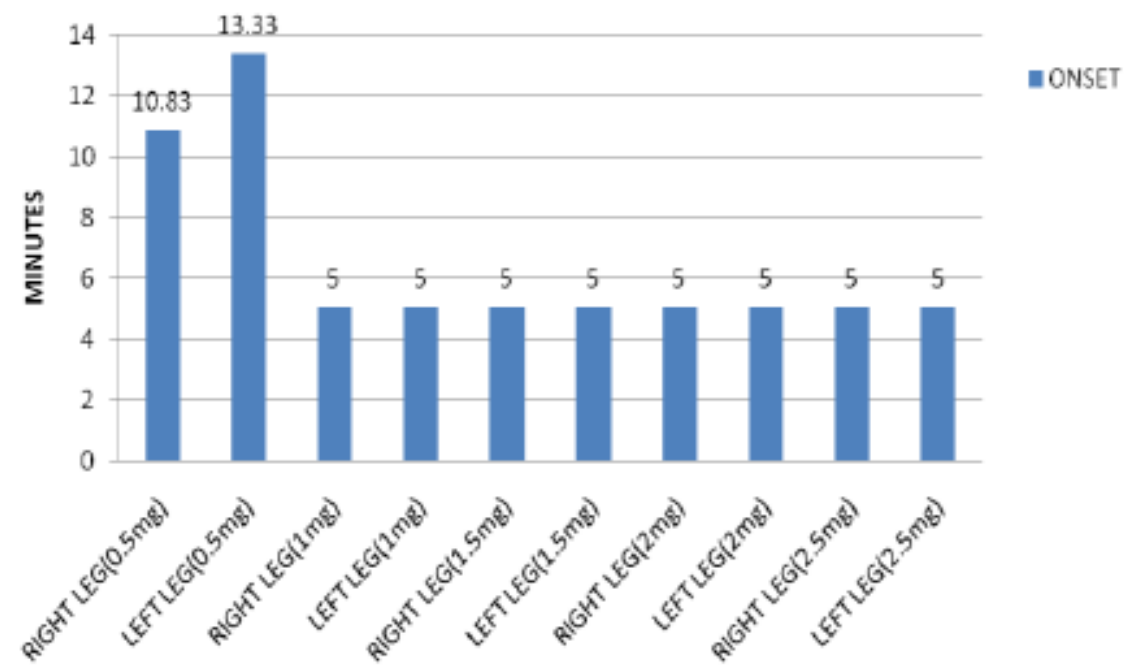

Figure. 2. Onset of eutectic mixture with different doses. (P value $<0.001)$

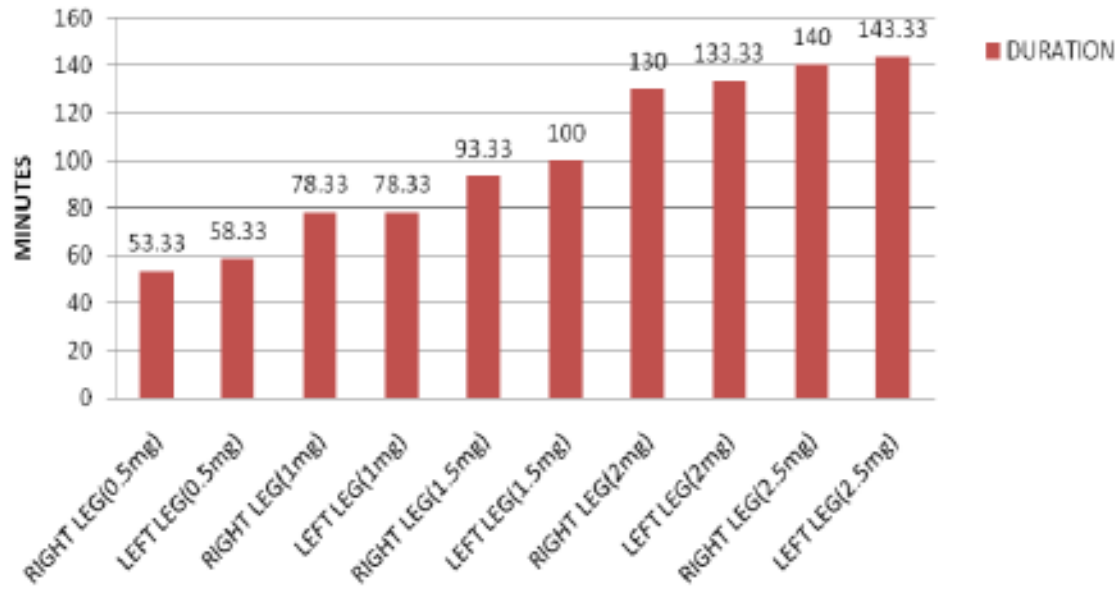

Figure. 3. Duration of eutectic mixture with different doses. (P-value $<0.001)$

\section{Discussion}

Several topical anesthetic preparations are available such as sprays (Xylocaine spray, Astra pharmaceuticals) and gels (xylocaine gel) are not effective in producing the topical anesthesia when applied to the intact skin of animals and they are highly effective when applied to mucus membranes. However, subcutaneous administration of local anesthetics produces anesthesia, but the procedure itself is painful. Brodin et al., (1984) and Evers et al., (1985) demonstrated the use of eutectic mixture (25mg/ml of lignocaine \& $25 \mathrm{mg} / \mathrm{ml}$ of prilocaine) together with an emulsifier, enables preparation of an oil and water emulsion with high base content in the emulsion with a low anesthetic concentration. This cream is commercially available as EMLA cream (Astra Pharmaceuticals., Ltd) and has gained wide acceptance in human medical practice for producing topical anesthesia on intact skin when applied under occlusive dressing. EMLA cream is highly effective in anesthetizing intact skin for performing pain free venipuncture in children (Ehrenstorm Reiz and Reiz., 1982; Hallen and Uppfeldt., 1982; Wahlstedz et al., 1984; Hopkins et al., 1988) and adults (Hallen et al., 1985). Young et al., (1987) and Price (1988) reported EMLA as an effective anesthetic for performing lumbar puncture in children. It is also proved to be effective as local anesthetic for performing superficial surgeries (Juhlin et al., 1980). In humans, the EMLA cream must be covered with an occlusive dressing and left in contact with skin for about 30 to 60 min (Hallen et al., 1984; Hopkins et al., 1988). A similar duration of treatment might be necessary for 
Texila International Journal of Basic Medical Science

Volume 2, Issue 1, Jul 2017

testing the topical anesthetic activity in animals. Based on the above reports, an attempt was made to study the onset and duration of topical anesthesia produced by EMLA cream in rabbits by employing a novel method "pedaling reflex in rabbits". Treatment with low dose of EMLA $(0.5 \mathrm{mg})$, the onset of action was longer. However, the onset of action observed with doses ranging from $1 \mathrm{mg}$ to $2.5 \mathrm{mg}$ remains constant i.e. 5min. A dose dependent increase in duration of anesthesia was observed with various doses of EMLA cream. This is an indicative of saturation of the drug after a particular dose in eliciting the action but duration of action continued to increase with proportionate increase of the dose. This will add to the existing knowledge.

\section{Conclusion}

The onset and duration of surface anesthetic EMLA cream not only depends up on the contact time but also on the dose of the eutectic mixture.

\section{References}

[1]. Brodin A, Nyqvist-Mayer A, Wadsten T, Forslund B \& Broberg F (1984). Phase diagram and aqueous solubility of the lidocaine-prilocaine binary system. Journal of Pharmaceutical Sciences 73, 481-484.

[2]. Ehrenstrom Reiz GME \& Reiz SLA (1982). EMLA-a eutectic mixture of local anesthetics for topical anesthesia. Acta Anaesthesiologica Scandinavia (Copenhagen) 26, 596-598.

[3]. Evers H, Von Dardel O, Juhlin L, Ohlsen L \& Vinnars E (1985). Dermal effects of composition based on the eutectic mixture of lignocaine and prilocaine (EMLA): studies in volunteers. British Journal of Anesthesia 57, 9971005 .

[4]. Hallen B \& Uppfeldt A (1982). Does lidocaine prilocaine cream permit pain free insertion of IV catheters in children? Anesthesiology 57, 340-342.

[5]. Hallen B, Olsson GL \& Uppfeldt A (1984). Pain free venipuncture: effect of timing of application of local anesthetic cream. Anesthesia 39, 969-972.

[6]. Hallen B, Carlsson P \& Uppfeldt A (1985). Clinical study of lignocaine-prilocaine cream to relieve the pain of venipuncture. British Journal of Anaesthesia 57, 326-328.

[7]. Hopkins CS, Buckley CJ \& Bush GH (1988). Pain free infection in infants. Anaesthesia 43, 198-201.

[8]. Juhlin L, Evers H \& Broberg F (1980). A lidocaine-prilocaine cream for superficial skin surgery and painful lesions. Acta Dermato-venereologica(Stockholm) 60, 544-546.

[9]. Price HV (1988). Lignocaine-prilocaine cream for lumbar puncture in children. Lancet ii (21), 1174.

[10]. Vogel HG (2002). Local anesthetic activity. Drug discovery and evaluation by HANS Gerhard Vogel 2nd edition, 655 .

[11]. Wahlstedt C, Kollberg H, Moller C \& Uppfeldt A (1984). Lidocaine-prilocaine cream reduces venipuncture pain. Lancet ii (14), 106.

[12]. Young AC, Shorchall A, Haynes W \& Young G (1987). Lignocaine-prilocaine cream for lumbar puncture. Lancet ii (26), 1533. 